\title{
Normal Sweat Secretion Despite Impaired Growth Hormone-Insulin-Like Growth Factor-I Axis in Obese Subjects
}

\author{
Michael Højby Rasmussen, ${ }^{1}$ Anders Juul, ${ }^{2}$ Katharina M. Main, ${ }^{2}$ and Jannik Hilsted ${ }^{1}$ \\ ${ }^{1}$ Department of Endocrinology, Hvidovre Hospital, University of Copenhagen, 2650 Copenhagen, Denmark \\ ${ }^{2}$ Department of Growth and Reproduction, Rigshospitalet, University of Copenhagen, 2100 Copenhagen, Denmark
}

Correspondence should be addressed to Michael Højby Rasmussen, mhr@novonordisk.com

Received 4 January 2011; Accepted 26 May 2011

Academic Editor: Dave Grattan

Copyright ( 2011 Michael Højby Rasmussen et al. This is an open access article distributed under the Creative Commons Attribution License, which permits unrestricted use, distribution, and reproduction in any medium, provided the original work is properly cited.

\begin{abstract}
Adults with GH deficiency are known to exhibit reduced sweating. Whether sweating capacity is impacted in obese subjects with impaired GH secretion have not previously been investigated. The main objective was to investigate sweat secretion rate and the GH-IGF-I axis in obese subjects before and after weight loss. Sixteen severely obese women $\left(\mathrm{BMI}, 40.6 \pm 1.1 \mathrm{~kg} / \mathrm{m}^{2}\right)$ were investigated before and after a diet-induced weight loss. Sixteen age-matched nonobese women served as controls. The obese subjects presented the characteristic decreased GH release, hyperinsulinaemia, increased FFA levels, and impaired insulin sensitivity, which all were normalised after diet-induced weight loss of $30 \pm 5 \mathrm{~kg}$. Sweat secretion rates were similar comparing obese and nonobese subjects ( $78 \pm 10$ versus $82 \pm 9 \mathrm{mg} / 30$ minutes) and sweat secretion did not change after a diet-induced weight loss in obese subjects. We conclude that although obese subjects have markedly reduced GH release and impaired IGF-I levels, sweat secretion rate is found to be normal.
\end{abstract}

\section{Introduction}

Sweating capacity as measured by sweat secretion rates has been reported reduced in adult patients with GH deficiency [1-4] as well as in children with GH deficiency (GHD) and GH insensitivity syndromes $[5,6]$. Furthermore, sweat secretion has been found correlated to circulating IGF-I levels $[1,4,7]$, and GH deficiency have been reported to have a profound effect on thermoregulation $[2,8]$. These observations in patients with GHD suggest that GH have a role in thermal regulation, via an effect on sweating capacity, and the reduced sweating is part of the abnormalities observed in patients with GHD $[7,9]$, as well as that some of the positive effects reported following GH replacement therapy might be due to a normalization of sweat secretion [7]. Normal sweating is of importance for maintaining correct temperature regulation and if disturbed can cause significant discomfort. The mechanism of GH action on sweating is not clear; however, GH receptors have been demonstrated on sweat glands, and GH may function as a trophic factor for sweat glands [10]. It has been suggested that GH hyper- and hyposecretory states result in changes in the growth and metabolic status of sweat glands, with alterations in sweat gland innervation [4] and a reduced number of sweat glands has been reported in adults with GHD [11].

Adults with GHD are characterised by perturbations in body composition, lipid metabolism, and cardiovascular risk profile [12]. It is well established that adult GHD usually is accompanied by an increase in fat accumulation and these changes in body composition are associated with metabolic derangements including insulin resistance [12]. Obese subjects as adults with GHD have multiple endocrine abnormalities including insulin resistance, severely suppressed spontaneous and stimulated GH release [13-15], and impaired circulating IGF-I levels [13]. The obesityassociated decrease in GH secretion is partially or fully recovered after diet-induced or surgical-induced reduction of fat mass $[13,14]$. In addition, sweat gland activity is reported impaired in obese subjects [16], and heat-waves can cause major discomfort to obese subjects. Although, the many similarities between adults with GHD and obese 
subjects are well recognised, there are no published data available on sweating capacity in obese subjects and the relationship to the GH-IGF-I axis. Thus, the primary aim of the study was to investigate sweat secretion rate in obese subjects as well as in relation to the GH-IGF-I axis and the impact of a diet-induced weight loss on sweating. Secondary objective was to relate sweat secretion and GH-IGF-I to endocrine abnormalities including hyperinsulinaemia, and elevated FFA often observed both in obese subjects and adults with GHD.

\section{Methods}

2.1. Subjects. We studied 16 obese female subjects, with a mean age of $29.5 \pm 1.4$ years and with a mean BMI of $40.6 \pm$ $1.1 \mathrm{~kg} / \mathrm{m}^{2}$; these were morbidly obese subjects, who underwent a diet-induced weight loss program. At the conclusion of the weight-loss program, 8 obese women completed the weight loss program with a weight-loss of approximately $30 \%$ of their initial body weight corresponding to a weightloss of $30 \pm 5 \mathrm{~kg}$ and a mean body mass index (BMI) of $27.0 \pm 1.4 \mathrm{~kg} / \mathrm{m}^{2}$. The remaining 8 obese women dropped out during the study due to lack of motivation. The control group consisted of 16 normal lean female subjects with a mean age of $27.0 \pm 1.1$ years and a mean BMI of $23.2 \pm$ $0.4 \mathrm{~kg} / \mathrm{m}^{2}$. All the subjects were nondiabetic and premenopausal. All the subjects gave informed consent. The revised Helsinki 2 Declaration was observed, and the study was approved by the Copenhagen Municipal Ethical Committee.

2.2. Weight-Loss Study. The obese subjects participated in a structured, outpatient weight-loss program where the goal was to achieve ideal body weight. During the initial phase the subjects consumed a commercial very-low-calorie diet that provided 1.6 megajoule $(\mathrm{MJ}) /$ day. The patients visited the outpatient clinic weekly for body weight measurements and nutrition counselling. When body weight had decreased to approximately $130 \%$ of ideal body weight, the patients were instructed to discontinue the $1.6 \mathrm{MJ} /$ day diet and begin consuming $5.0 \mathrm{MJ} /$ day diet of normal food items. During this period, the patients used the diet and nutrition materials that had been supplied to them and discussed during the counselling sessions. When ideal body weight was achieved or when no further weight could be lost, the patients were instructed to begin consuming a basic $8.0 \mathrm{MJ} / \mathrm{d}$ diet ( $15 \%$ protein, $55 \%$ carbohydrate, and $30 \%$ fat) which was individually adjusted for each patient to obtain energy balance. Energy intake was further adjusted down or up for each subject on a weekly basis (during weekly dietary counselling) to reach a final, stable body weight (e.g., if body weight began to increase, daily energy intake was reduced). Sampling in the postobese patients was performed after body weight had remained stable $( \pm 1.5 \mathrm{~kg})$ for $\geq 1$ month after switching to the last diet.

2.3. Twenty-Four-Hour Study. For each 24-h sampling period the subjects were admitted to the metabolic ward at 07:30 AM. after an overnight fast. A cannula (Viggo AB,
Vingmed, Denmark) was placed in a forearm vein. Blood withdrawal commenced $30 \mathrm{~min}$ after venipuncture through a nonthrombogenic catheter (Carmeda; Viggo AB, Vingmed, Denmark) inserted through the cannula and connected to an automatic constant withdrawal pump (withdrawal rate was $3.5 \mathrm{~mL} / \mathrm{h}$ ). Collection tubes were changed at 20 -min intervals over the following 24-h period giving a series of 72 sequential samples for each subject. The technique allows the participants to sleep during the night and to move freely around during the day. For GH measurements all 72 serum samples were assayed (total $n=5760$ ). The basal blood samples were taken after the subjects had fasted overnight.

2.4. Analyses. Evaluation of sweat secretion was performed as previously described [17]. In the resting subject, sweating was induced on the flexor side of the distal forearm by iontophoresis with $0.2 \%$ pilocarpine chloride, using a current of $2 \mathrm{~mA}$ for 5 minutes. Two filter papers (Whatman Ashless Roundfilters, diameter $2 \mathrm{~cm}$ ) were soaked in pilocarpine solution and were positioned underneath the electrode. Two quadrangular negative electrodes (size $3 \times 3 \mathrm{~cm}$ ) were placed on the flexor side of the upper arm. After 5 minutes, the area of iontophoresis was rinsed with deionized water and $61 \%$ ethanol and dried thoroughly. Sweat was collected for a 30 minute-period with the three filter papers sealed with roundel of plastic tape to prevent evaporation. Sweat mass was measured by weighing filter paper (Mettler Scales, precision $\pm 0.1 \mathrm{mg}$ ) before and after collection.

Serum GH concentration was determined using a timeresolved immunofluorometric assay (TR-IFMA, PerkinElmer LifeSciences, Türku, Finland). IGF-I was determined in acid-ethanol-extracted serum by a specific radioimmunoassay [18]. Insulin was determined using an enzyme-linked two-site immunoassay as described by Andersen et al. [19]. FFA concentrations were determined by a previously described microfluorometric method [20].

2.5. Calculations. The area under the curve (AUC) of 24hour GH release was estimated above the zero level as previously described [21]. The Quantitative Insulin Sensitivity Check Index (QUICKI) was calculated from the fasting insulin and glucose values; QUICKI $=1 /[\log$ insulin + log glucose] as described by Katz et al. [22]. Body mass index was calculated as weight $(\mathrm{kg}) /$ height $\left(\mathrm{m}^{2}\right)$. Body weight was measured to the nearest $0.1 \mathrm{~kg}$ with an electronic scale (Seca 070; Seca, Copenhagen). Twenty-four-hour GH release and IGF-I data have previously been reported separately [23].

2.6. Statistics. Mann-Whitney rank sum test was used when comparing data between different groups (unpaired data). Wilcoxon signed rank test was applied when comparing paired data from the previously obese subjects to the same eight subjects in the prediet obese state. Linear regression analysis was performed to identify independent effects of hormonal factors (FFA, insulin, and IGF-I) on 24-h GH release. Unless otherwise stated, all data are expressed as mean \pm SEM. The level of statistical significance was set at $P<0.05$. 


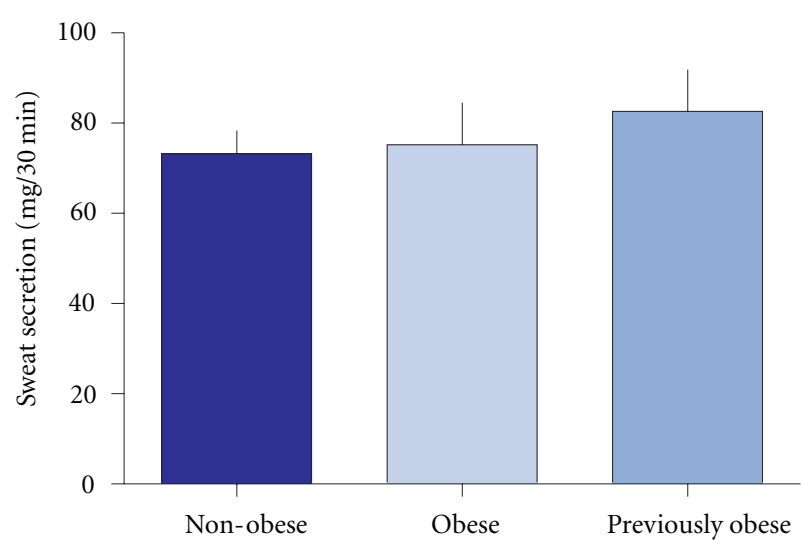

FIGURE 1: Sweat secretion rate. Columns represent (left to right) levels in non-obese $(n=16)$, obese $(n=16)$, and previously obese subjects $(n=8)$.

\section{Results}

3.1. Weight-Loss Study. At the conclusion of the weight-loss program, the 8 obese women that completed the weight loss program had lost approximately 30\% of their initial body weight $(30 \pm 5 \mathrm{~kg})$. The remaining 8 obese women dropped out during the study due to lack of motivation.

3.2. Sweat Secretion. Sweat secretion was similar in obese and non-obese women ( $75 \pm 9$ versus $73 \pm 5 \mathrm{mg} / 30 \mathrm{~min})$, and no change in sweat secretion occurred after diet-induced weight loss (Figure 1).

3.3. 24-Hour GH Release and IGF-I Levels. Twenty-fourhour GH release was found to be reduced in obese women compared to non-obese women (Figure 2). A significant increase in $\mathrm{GH}$ levels was observed after weight loss, and no significant difference was present between previously obese and non-obese women (Figure 2). Basal levels of IGF-I were significantly lower in obese women at preweight loss compared to non-obese women and a significant increase was observed in IGF-I levels after weight loss, and no significant difference was present between previous obese and nonobese women (Table 1). Twenty-four-hour GH release and IGF-I data have previously been reported separately [23].

3.4. Insulin and FFA. FFA as well as insulin levels were found elevated (Table 1). No significant difference in FFA or insulin levels was present after weight loss between previously obese and non-obese women (Table 1).

3.5. Insulin Sensitivity. Insulin sensitivity estimated by the QUICKI formula was decreased in obese women compared to non-obese women. A significant increase in insulin sensitivity was observed after weight loss, and no significant difference was present between previously obese and nonobese women (Table 1).

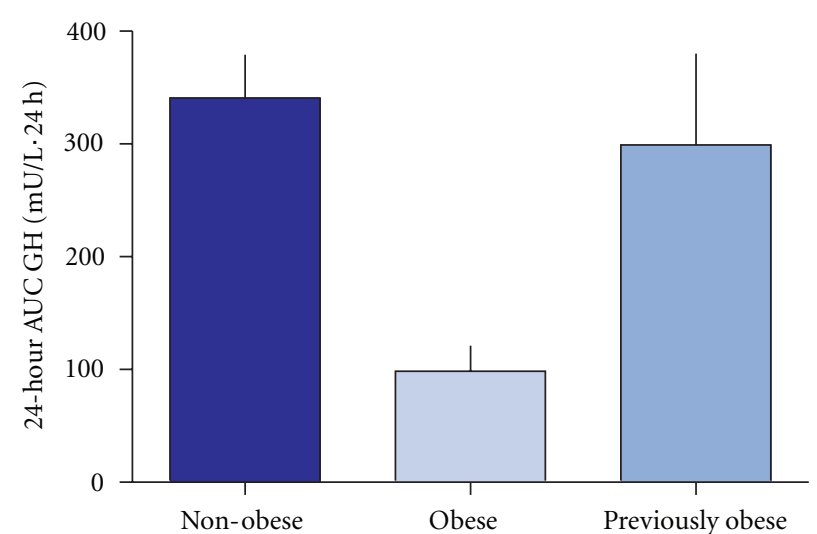

FIgURE 2: Twenty-four-hour GH release. Columns represent (left to right) levels in non-obese $(n=16)$, obese $(n=16)$, and previously obese subjects $(n=8)$.

TABLe 1: Twenty-four-hour GH, basal levels of insulin, FFA, IGF-I levels, and insulin sensitivity in 16 obese, 8 previously obese, and 16 non-obese.

\begin{tabular}{lccc}
\hline & Non-obese & Obese & $\begin{array}{c}\text { Previously } \\
\text { obese }\end{array}$ \\
\hline $\begin{array}{l}\text { 24-hour AUC GH } \\
(\mathrm{mU} / \mathrm{L} \cdot 24 \mathrm{~h})\end{array}$ & $341 \pm 41$ & $99 \pm 23^{*}$ & $299 \pm 81^{\ddagger}$ \\
IGF-I $(\mu \mathrm{g} / \mathrm{L})$ & $308 \pm 18$ & $220 \pm 21^{*}$ & $330 \pm 73^{\ddagger}$ \\
FFA $(\mathrm{meq} / \mathrm{L})$ & $0.55 \pm 0.07$ & $0.80 \pm 0.07^{* *}$ & $0.63 \pm 0.08^{\ddagger}$ \\
Insulin $(\mathrm{pmol} / \mathrm{L})$ & $46.8 \pm 3.6$ & $81.9 \pm 7.8^{*}$ & $43.3 \pm 9.1^{\ddagger}$ \\
QUICKI $(\mathrm{no}$ & $0.38 \pm 0.01$ & $0.33 \pm 0.01^{*}$ & $0.39 \pm 0.01^{\ddagger}$ \\
units $)$ & & \\
${ }^{*} P<0.001$ Obese versus non-obese. & & \\
${ }^{* *} P<0.05$ Obese versus non-obese. \\
${ }^{\ddagger} P<0.05$ Obese versus previously obese.
\end{tabular}

TABle 2: Correlations between 24-hour GH release, IGF-I, FFA insulin, and insulin sensitivity in all subjects (non-obese, obese, and previously obese subjects).

\begin{tabular}{ll}
\hline & 24-hour GH release \\
\hline Insulin & $r=-0.59 ; P<0.001$ \\
QUICKI & $r=0.72 ; P<0.00001$ \\
FFA & $r=-0.10 ; n s$ \\
IGF-I & $r=0.10 ; n s$ \\
\hline
\end{tabular}

3.6. Relationships between Insulin, Insulin Sensitivity, FFA, IGF-I, and 24-Hour GH Release. Regression analysis performed considering non-obese, obese, and previously obese subjects showed a significant positive correlation between insulin sensitivity and 24-hour GH release (Table 2).

\section{Discussion}

We have previously reported 24-h GH release and IGF-I levels to be impaired in obese subjects and normalised after 
diet-induced weight loss [23]. The novel data reported now imply that although GH deficiency and obesity in adults feature many similarities, we did not observe an impact on sweating capacity in the obese subjects despite markedly reduced spontaneous GH release and impaired circulating IGF-I levels. Thus, the subnormal sweat secretion rate in adults with GH deficiency reported in previous studies [1-4] as well as the positive correlations between circulating IGF-I levels and sweat secretion rate in these patients [1] may be specifically related to severe GH deficiency and not impaired GH-IGF-I axis per se. One explanation for the difference could be damage to the thermoregulatory centre in these patients with pituitary disease; however, parts of the GHIGF axis seem to be present in human sweat glands $[10,24]$. It could be speculated whether the normal sweat secretion observed in obese subjects with impaired GH-IGF-I axis adds further evidence that the criterion for the diagnosis of GHD in obese patients is complex. The mechanism behind the role of GH and IGF-I in sweat gland function remains speculative, and it cannot be ruled out that other factors than the GHIGF-I axis in obese subjects are involved in the more profuse sweat secretion observed, although good correlation between whole body sweat secretion and regional sweat secretion rate has been reported [17].

A secondary objective of the study was to relate sweat secretion and GH-IGF-I to hyperinsulinaemia and elevated FFA often observed in obese subjects. Insulin and FFA are two of the main peripheral signals proposed to be interwined with the impaired GH release observed in obesity. We found no relationship between sweat secretion and insulin, or FFA levels. However, our data suggest that the decreased spontaneous 24-hour GH release observed in obesity seems related to the concomitant hyperinsulinaemia and insulin sensitivity rather than elevated FFA levels.

It has previously been reported that hyperinsulinaemia results in suppressed pituitary GH release [25-27]. In addition, circulating elevated FFAs have been suggested to be involved in the mechanism behind the hyposomatropism observed in obesity $[28,29]$. In the present study, circulating FFA levels were significantly increased in obese subjects as reported by others; however, FFA levels were apparently not associated with the impaired physiological GH release. The improved GH response to stimulation tests in obese subjects pretreated with acipimox has been suggesting elevated FFA levels to be involved in the mechanism behind the GH hyposecretion observed in obesity $[28,29]$. However, it is noteworthy that acipimox-induced decrease in FFA did not have an impact on physiological GH secretion [28]. Considering that acipimox is known to strongly reduce serum insulin in obese patients [30], it is speculated whether reductions in insulin levels per se might explain the magnitude of the acipimox-induced improvement in GH response. This can likely be explained as when insulin levels are significantly increased, insulin's role overcomes the effect of FFA on the GH release.

In conclusion, we did not observe an impact on sweating capacity in the obese subjects despite markedly reduced spontaneous GH release and impaired circulating IGF-I levels.

\section{References}

[1] S. A. Pedersen, K. Welling, K. F. Michaelsen, J. O. Jorgensen, J. S. Christiansen, and N. E. Skakkebaek, "Reduced sweating in adults with growth hormone deficiency," Lancet, vol. 2, no. 8664, pp. 681-682, 1989.

[2] A. Juul and N. E. Skakkebaek, "Growth hormone deficiency and hyperthermia," Lancet, vol. 338, no. 8771, p. 887, 1991.

[3] S. B. Sneppen, K. M. Main, A. Juul et al., "Sweat secretion rates in growth hormone disorders," Clinical Endocrinology, vol. 53, no. 5, pp. 601-608, 2000.

[4] W. Hasan, T. Cowen, P. S. Barnett, E. Elliot, P. Coskeran, and P. M. G. Bouloux, "The sweating apparatus in growth hormone deficiency, following treatment with $\mathrm{r}-\mathrm{hGH}$ and in acromegaly," Autonomic Neuroscience: Basic and Clinical, vol. 89, no. 1-2, pp. 100-109, 2001.

[5] K. Main, K. O. Nilsson, and N. E. Skakkebaek, "Influence of sex and growth hormone deficiency on sweating," Scandinavian Journal of Clinical and Laboratory Investigation, vol. 51, no. 5, pp. 475-480, 1991.

[6] K. M. Main, D. A. Price, M. O. Savage, and N. E. Skakkebae, "Decreased sweating in seven patients with Laron syndrome," Journal of Clinical Endocrinology and Metabolism, vol. 77, no. 3, pp. 821-823, 1993.

[7] J. Sandahl Christiansen, J. O. Jorgensen, S. A. Pedersen et al., "GH-Replacement therapy in adults," Hormone Research, vol. 36, supplement 1, pp. 66-72, 1991.

[8] A. Juul, A. Behrenscheer, T. Tims, B. Nielsen, J. HalkjaerKristensen, and N. E. Skakkebaek, "Impaired thermoregulation in adults with growth hormone deficiency during heat exposure and exercise," Clinical Endocrinology, vol. 38, no. 3, pp. 237-244, 1993.

[9] A. Juul, N. Hjortskov, L. T. Jepsen et al., "Growth hormone deficiency and hyperthermia during exercise: a controlled study of sixteen GH-deficient patients," Journal of Clinical Endocrinology and Metabolism, vol. 80, no. 11, pp. 3335-3340, 1995.

[10] S. R. Oakes, K. M. Haynes, M. J. Waters, A. C. Herington, and G. A. Werther, "Demonstration and localization of growth hormone receptor in human skin and skin fibroblasts," Journal of Clinical Endocrinology and Metabolism, vol. 75, no. 5, pp. 1368-1373, 1992.

[11] M. Lange, J. Thulesen, U. Feldt-Rasmussen et al., "Skin morphological changes in growth hormone deficiency and acromegaly," European Journal of Endocrinology, vol. 145, no. 2, pp. 147-153, 2001.

[12] P. V. Carroll, E. R. Christ, B. Å. Bengtsson et al., "Growth hormone deficiency in adulthood and the effects of growth hormone replacement: a review," Journal of Clinical Endocrinology and Metabolism, vol. 83, no. 2, pp. 382-395, 1998.

[13] M. H. Rasmussen, A. Hvidberg, A. Juul et al., "Massive weight loss restores 24-hour growth hormone release profiles and serum insulin-like growth factor-I levels in obese subjects," Journal of Clinical Endocrinology and Metabolism, vol. 80, no. 4, pp. 1407-1415, 1995.

[14] L. De Marinis, A. Bianchi, A. Mancini et al., "Growth hormone secretion and leptin in morbid obesity before and after biliopancreatic diversion: relationships with insulin and body composition," Journal of Clinical Endocrinology and Metabolism, vol. 89, no. 1, pp. 174-180, 2004.

[15] S. Savastano, C. Di Somma, A. Belfiore et al., "Growth hormone status in morbidly obese subjects and correlation with body composition," Journal of Endocrinological Investigation, vol. 29, no. 6, pp. 536-543, 2006. 
[16] L. García Hidalgo, "Dermatological complications of obesity," American Journal of Clinical Dermatology, vol. 3, no. 7, pp. 497-506, 2002.

[17] N. Hjortskov, L. T. Jepsen, B. Nielsen, A. Juul, and N. E. Skakkebaek, "Pilocarpine iontophoresis test: an index of physiological sweat secretion?” Clinical Physiology, vol. 15, no. 4, pp. 409-414, 1995.

[18] A. Juul, P. Bang, N. T. Hertel et al., "Serum insulin-like growth factor-I in 1030 healthy children, adolescents, and adults: relation to age, sex, stage of puberty, testicular size, and body mass index," Journal of Clinical Endocrinology and Metabolism, vol. 78, no. 3, pp. 744-752, 1994.

[19] L. Andersen, B. Dinesen, P. N. Jorgensen, F. Poulsen, and M. E. Røder, "Enzyme immunoassay for intact human insulin in serum or plasma," Clinical Chemistry, vol. 39, no. 4, pp. 578$582,1993$.

[20] J. Miles, R. Glasscock, J. Aikens, J. Gerich, and M. Haymond, "A microfluorometric method for the determination of free fatty acids in plasma," Journal of Lipid Research, vol. 24, no. 1, pp. 96-99, 1983.

[21] G. R. Merriam and K. W. Wachter, "Algorithms for the study of episodic hormone secretion," The American Journal of Physiology, vol. 243, no. 4, pp. E310-E318, 1982.

[22] A. Katz, S. S. Nambi, K. Mather et al., "Quantitative insulin sensitivity check index: a simple, accurate method for assessing insulin sensitivity in humans," Journal of Clinical Endocrinology and Metabolism, vol. 85, no. 7, pp. 2402-2410, 2000.

[23] M. H. Rasmussen, A. Juul, and J. Hilsted, "Effect of weight loss on free insulin-like growth factor-I in obese women with hyposomatotropism," Obesity, vol. 15, no. 4, pp. 879-886, 2007.

[24] E. Hodak, A. B. Gottlieb, M. Anzilotti, and J. G. Krueger, "The insulin-like growth factor I receptor is expressed by epithelial cells with proliferative potential in human epidermis and skin appendages: correlation of increased expression with epidermal hyperplasia," Journal of Investigative Dermatology, vol. 106, no. 3, pp. 564-570, 1996.

[25] J. U. Weaver, K. Noonan, and P. G. Kopelman, "An association between hypothalamic-pituitary dysfunction and peripheral endocrine function in extreme obesity," Clinical Endocrinology, vol. 35, no. 1, pp. 97-102, 1991.

[26] J. L. Clasey, A. Weltman, J. Patrie et al., "Abdominal visceral fat and fasting insulin are important predictors of 24-hour GH release independent of age, gender, and other physiological factors," Journal of Clinical Endocrinology and Metabolism, vol. 86, no. 8, pp. 3845-3852, 2001.

[27] R. M. Luque and R. D. Kineman, "Impact of obesity on the growth hormone axis: evidence for a direct inhibitory effect of hyperinsulinemia on pituitary function," Endocrinology, vol. 147, no. 6, pp. 2754-2763, 2006.

[28] F. Cordido, R. Peino, A. Peñalva, C. V. Alvarez, F. F. Casanueva, and C. Dieguez, "Impaired growth hormone secretion in obese subjects is partially reversed by acipimoxmediated plasma free fatty acid depression," Journal of Clinical Endocrinology and Metabolism, vol. 81, no. 3, pp. 914-918, 1996.

[29] A. E. Pontiroli, M. F. Manzoni, M. E. Malighetti, and R. Lanzi, "Restoration of growth hormone $(\mathrm{GH})$ response to GH-releasing hormone in elderly and obese subjects by acute pharmacological reduction of plasma free fatty acids," Journal of Clinical Endocrinology and Metabolism, vol. 81, no. 11, pp. 3998-4001, 1996.
[30] D. Worm, J. E. Henriksen, A. Vaag, P. Thye-Rønn, A. Melander, and H. Beck-Nielsen, "Pronounced blood glucose-lowering effect of the antilipolytic drug acipimox in noninsulindependent diabetes mellitus patients during a 3-day intensified treatment period," Journal of Clinical Endocrinology and Metabolism, vol. 78, no. 3, pp. 717-721, 1994. 


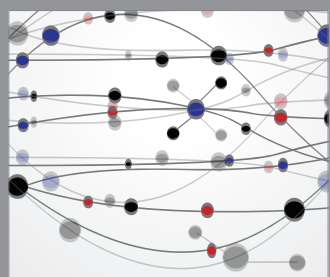

The Scientific World Journal
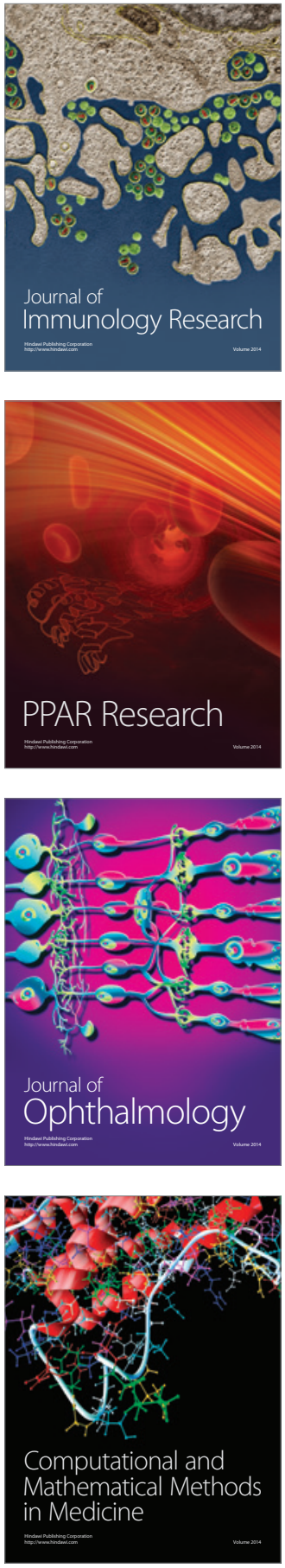

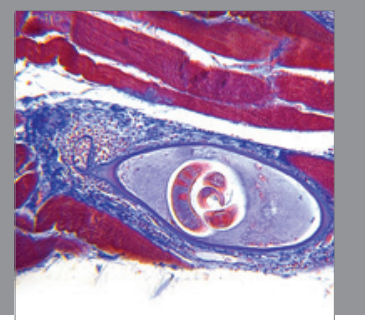

Gastroenterology

Research and Practice
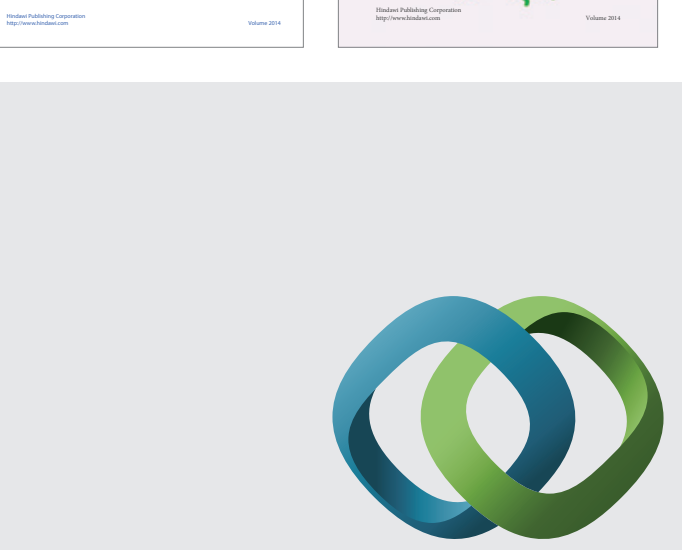

\section{Hindawi}

Submit your manuscripts at

http://www.hindawi.com
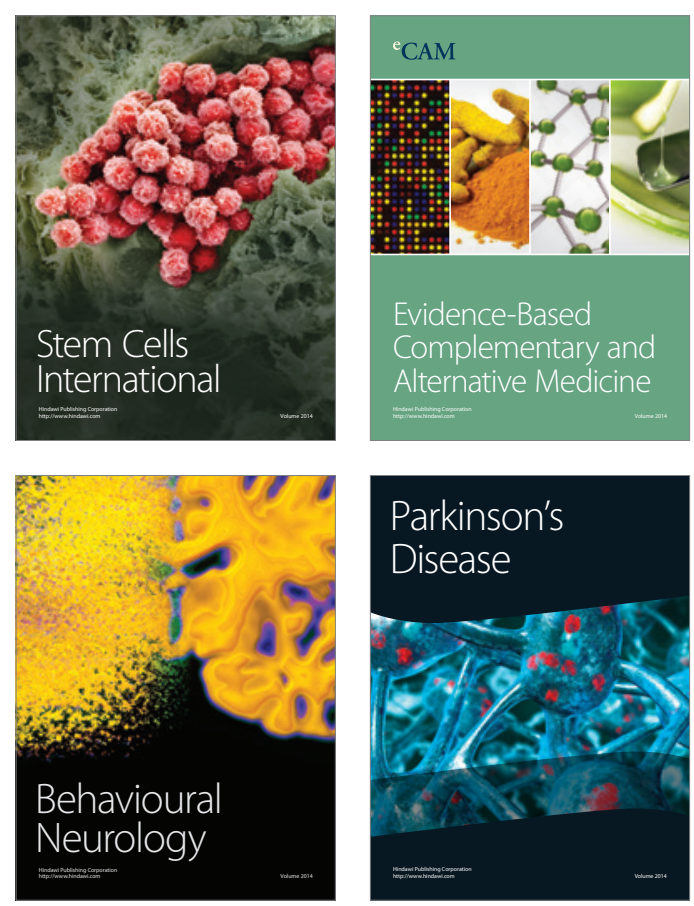

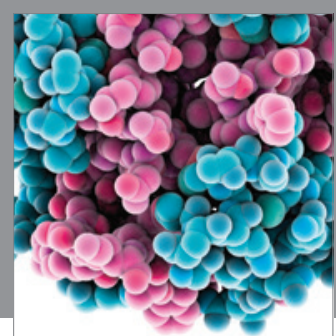

Journal of
Diabetes Research

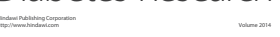

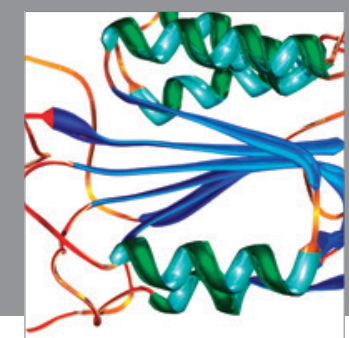

Disease Markers
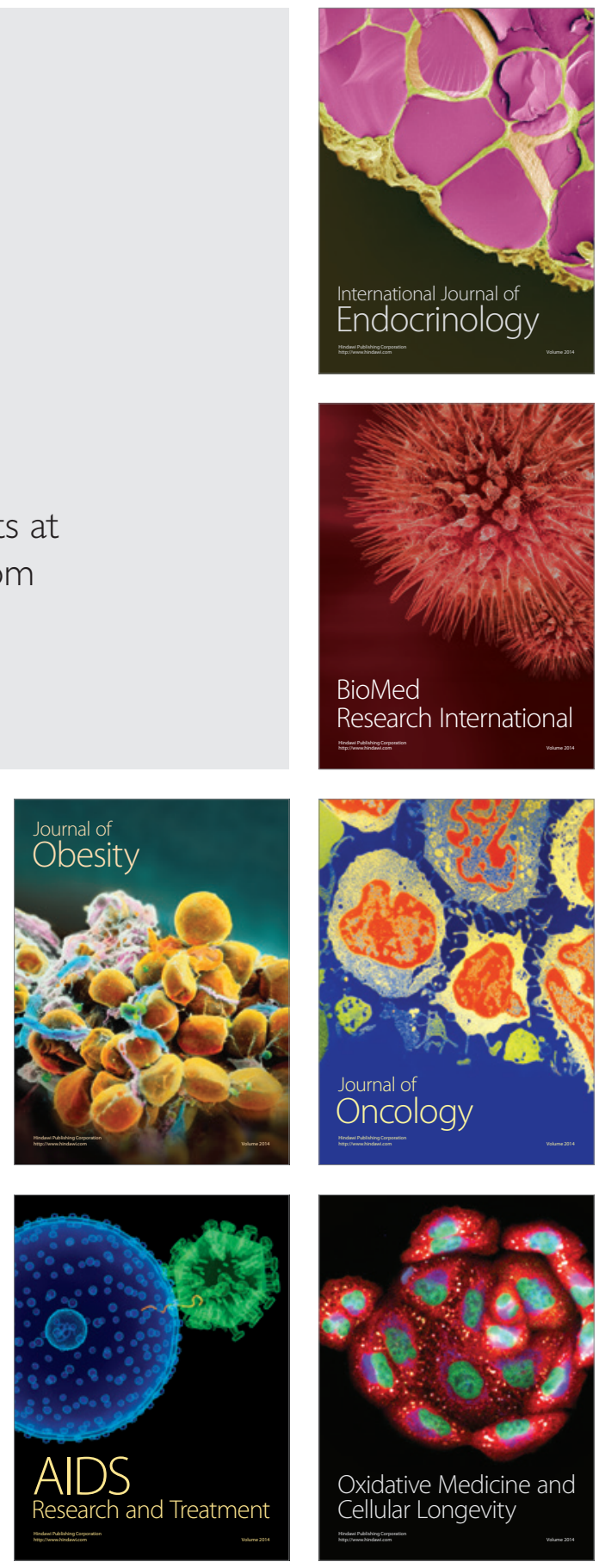